\title{
The "Golden Angels": effects of trained volunteers on specialling and readmission rates for people with dementia and delirium in rural hospitals
}

\author{
Annaliese Blair, 1,2,3 Katrina Anderson ${ }^{1,2,3}$ and Catherine Bateman ${ }^{1,2}$ \\ ${ }^{1}$ Aged Care Evaluation Unit, Southern NSW Local Health District, Queanbeyan, New South Wales, Australia \\ ${ }^{2}$ NHMRC Cognitive Decline Partnership Centre, Sydney, Australia \\ ${ }^{3}$ Australian National University, Canberra, Australia
}

Objectives: Evaluate the clinical outcomes for patients with dementia, delirium, or at risk for delirium supported by the person-centered volunteer program in rural acute hospitals.

Design: A non-randomized, controlled trial.

Participants: Older adults admitted to seven acute hospitals in rural Australia. Intervention $(n=270)$ patients were $>65$ years with a diagnosis of dementia or delirium or had risk factors for delirium and received volunteer services. Control $(n=188)$ patients were admitted to the same hospital 12 months prior to the volunteer program and would have met eligibility criteria for the volunteer program, had it existed.

Intervention: Trained volunteers provided 1:1 person-centered care with a focus on nutrition and hydration support, hearing and visual aids, activities, and orientation.

Measures: Medical record audits provided data on volunteer visits, diagnoses, length of stay (LOS), behavioral incidents, readmission, specialling, mortality, admission to residential care, falls, pressure ulcers, and medication use.

Results: Across all sites, there was a significant reduction in rates of $1: 1$ specialling and 28 day readmission for patients receiving the volunteer intervention. LOS was significantly shorter for the control group. There were no differences in other patient outcomes for the intervention and control groups.

Conclusion: The volunteer intervention is a safe, effective, and replicable way to support older acute patients with dementia, delirium, or risk factors for delirium in rural hospitals. Further papers will report on cost effectiveness, family carer, volunteer, and staff experiences of the program.

Key words: dementia, delirium, psychosocial interventions, rural, inpatient, hospital, volunteers

\section{Introduction}

\section{Background}

People with dementia and/or delirium are at heightened risk of adverse events, such as falls and mortality in the acute care setting (Inouye et al., 2013). They can also manifest distressing, agitated and aggressive behaviors, or conversely be sleepy and withdrawn making them more susceptible to becoming dehydrated and malnourished. Rather than using person-centered care (Kitwood, 1997)

Correspondence should be addressed to: Annaliese Blair, Aged Care Evaluation Unit, PO Box 1845, Queanbeyan, New South Wales 2620, Australia. Phone: +61-2-6150-7551. Email: Annaliese.Blair@health.nsw.gov.au. Received 21 Jan 2018; revision requested 2 May 2018; revised version received 10 May 2018; accepted 12 May 2018. First published online 13 August 2018. to prevent or treat causes of these behaviors, patients with cognitive impairment may be physically restrained, given 1:1 supervision (specialled), or treated (often inappropriately) with psychotropic medications, resulting in significant negative side effects (Sink et al., 2005; Inouye et al., 2014; Maust et al., 2015). These responses contribute to greater social and economic costs.

Internationally, multicomponent nonpharmacological delirium prevention interventions are effective in reducing delirium incidence and preventing falls, with a trend toward decreasing length of stay (LOS) and avoiding institutionalization (Hshieh et al., 2015; Siddiqi et al., 2016). However, acute care environments are often not adequately resourced to provide 
recommended preventative and person-centered care for people with dementia and/or delirium (Clissett et al., 2013; Dewing and Dijk, 2016).

In metropolitan hospitals around the world, volunteers have been successfully utilized to assist specialist staff such as geriatricians to provide multicomponent delirium preventative care for older people. The Helping Elder Life Program in the USA resulted in reduced incidence of delirium, reduced LOS, improved satisfaction for patients, families and staff, and sustained cost savings (Inouye et al., 2000; Rizzo et al., 2001; Rubin et al., 2011). An Australian study found statistically significant reductions in the incidence and severity of delirium, and half the number of hours of $1: 1$ specialling required by Assistants in Nursing (or $\$ 4,775$ per bed, per year savings on staff costs) (Caplan and Harper, 2007).

However, these programs are set in large metropolitan hospitals and require specialist staff and geriatrician resources. This limits its transferability, particularly in less densely populated and geographically remote rural areas in Australia and, internationally, where specialist resources are nonexistent or limited.

The Dementia \& Delirium Care with Volunteers $($ program (DDCVP) was developed to address this service gap in rural areas of Australia. The intervention involves recruiting and training volunteers to provide person-centered, one-to-one practical assistance (including therapeutic activities and assistance with eating/drinking/walking and using hearing/visual aids) and emotional support for people with dementia and/or delirium admitted to rural hospitals.

Findings from a pilot study $(N=64)$ suggest improved patient outcomes such as reduction in time spent in hospital, and enhanced safety, hydration and nutrition, and increase in analgesic medications (Bateman et al., 2016). The volunteers were well accepted and became known as "Golden Angels" due to their gold colored uniform and compassionate care. The original program has been sustained for 8 years and replicated in a number of hospitals.

\section{The study}

This paper reports patient clinical outcomes from a more extensive evaluation of the clinical outcomes of the DDCVP at seven rural hospitals in Southern NSW. It expands on the pilot evaluation by examining a larger sample across seven sites with an historic control group. Cost-effectiveness data, changes to staff processes, and outcomes for volunteers, staff and family carers will be reported in subsequent publications.

\section{Method}

\section{Ethical considerations}

The study was approved by the appropriate Human Research Ethics Committee (Project Number HREC/15/GWAHS/63) and received site specific approval at each hospital site.

If the patient was considered unable to provide informed written consent on his/her own behalf, due to cognitive impairment, written consent was sought from an appropriate substitute decision maker. Where it was impracticable to obtain written consent (e.g. historical control patients, deceased patients, and short-stay patients), de-identified data on the patient's hospital stay was provided by the participating hospital.

\section{Study design}

The study involved a non-randomized controlled trial using historic patients as a control group.

Randomization of patients and wards was not possible as many of the hospitals only had one ward and the intervention impacted the entire ward. Blinding of those collecting data from medical records was not possible as it was evident in the medical record that patients were receiving the intervention.

\section{Setting}

The study was conducted in seven acute rural hospitals located in Southern NSW Local Health District (SNSWLHD), which serves a population of 200,000 people over an area of 45,000 square kilometres. All SNSW LHD acute hospitals which had not yet received the program were invited to participate. All agreed to provide appropriate support and were thus included. The hospitals ranged from 13 to 79 bed capacity $(M=41.14$, $\mathrm{SD}=20.37$ ), most with only one ward. For those with multiple wards, the focus was on acute general medical and surgical wards. Sub-acute wards (e.g. rehabilitation) were excluded from analyses.

\section{Participants}

Two participant groups were involved as follows:

1. Patients receiving volunteer care.

2. Historical control patients who were admitted to the same facility 12 months prior to commencement of the program and who would have been eligible for the volunteer program, had it existed.

Table 1 outlines the inclusion and exclusion criteria for each participant group.

Of the 590 referrals to the volunteer program, 270 individual patients were seen by the volunteers and met the research inclusion criteria. The control 
Table 1. Inclusion and exclusion criteria for study participant groups

\begin{tabular}{|c|c|}
\hline PARTICIPANT GROUP & INCLUSION/EXCLUSION \\
\hline $\begin{array}{l}\text { 1. Patients receiving volunteer } \\
\text { care }(n=270)\end{array}$ & $\begin{array}{l}\text { Patient research participants must be eligible for and participating in the volunteer } \\
\text { program. That is they must: } \\
\text { - be over } 65 \text { years (or over } 45 \text { years if Aboriginal or Torres Strait Islander); and } \\
\text { - have cognitive impairment as evidenced by either a score } 24 / 30 \text { or less on a Standard } \\
\text { Mini Mental State Examination (SMMSE) or a diagnosis of dementia; } \\
\text { - or be positive for suggested delirium with the Confusion Assessment Method (CAM); } \\
\text { - or over } 65 \text { years (or } 45 \text { years) and have one or more of the following delirium risk } \\
\text { factors: cognitive impairment, fractured Neck of Femur (\#NOF), Visual or hearing } \\
\text { impairment, severe medical illness, dehydration, previous history of delirium, } \\
\text { depression. } \\
\text { Patients were excluded if: } \\
\text { - they display behaviours such as aggression which make it unsafe for volunteers to care } \\
\text { for them; } \\
\text { - they (or a substitute decision maker) decline to be part of the volunteer program and/or } \\
\text { the research study. }\end{array}$ \\
\hline $\begin{array}{l}\text { 2. Historical control patients } \\
(n=188)\end{array}$ & $\begin{array}{l}\text { Controls were selected using stratified random sampling. That is, patients: } \\
\text { - Admitted to an intervention ward, over a six month period, beginning } 12 \text { months before } \\
\text { the beginning of the intervention (approx. February to July 2015); } \\
\text { - Who would have met eligibility criteria for the program had it existed at the time (see } \\
\text { above for program eligibility); and } \\
\text { - Were admitted for greater than } 24 \text { hours. }\end{array}$ \\
\hline
\end{tabular}

group of 188 patients was chosen randomly from a pool of all patients who were admitted to acute care in the same hospitals 12 months before the volunteer project began and would have met inclusion criteria for the program.

As seen in Table 2, both groups consisted of patients with a median age of 83 years (MannWhitney $z=1.003, \mathrm{p}=0.316)$, with a large degree of poly-pharmacy $(M=8.38 ; t(448)=0.939, \mathrm{p}=$ 0.348 ) and multiple physical co-morbidities ( $\mathrm{Mdn}$ $=6$; Mann-Whitney $z=-0.490, \mathrm{p}=0.624$ ), such as diabetes, ischemic heart disease, hypertension etc. The groups had similar proportions of female patients $\left(\chi^{2}(1, N=458)=0.20, \mathrm{p}=0.656\right)$, those with a formal diagnosis of dementia $\left(\chi^{2}(1, N=\right.$ $457)=1.57, \mathrm{p}=0.211$ ), a diagnosis of delirium $\left(\chi^{2}(1, N=455)=1.26, \mathrm{p}=0.262\right)$, and those on psychotropic medications $\left(\chi^{2}(1, N=453)=1.64\right.$, $\mathrm{p}=0.200)$ and analgesics at admission $\left(\chi^{2}(1, N=\right.$ $454)=0.279, \mathrm{p}=0.598$ ).

\section{The intervention}

Volunteer Dementia and Delirium Care Implementation and Training resource (C) (NSW Agency for Clinical Innovation, 2014) was used by sitebased implementation staff to ensure consistency with the process of implementation and volunteer training. The resource package contained

1. An implementation guide with project plan.

2. An eight session group training program for volunteers on dementia and delirium and their role.
3. Generic program procedures which were adapted for the different hospital routines.

The resource developer (CB) provided regular individual and group mentoring to the site implementation staff throughout the implementation process. Training sessions were provided for ward staff on dementia and delirium, the program structure, referral process, and the role and boundaries of the volunteers.

Once trained, the volunteers were provided with orientation to the ward and support by site implementation staff. They provided care over two shifts each weekday. In most sites, shifts were between $8 \mathrm{am}$ to $12: 30 \mathrm{pm}$ and $3 \mathrm{pm}$ to $7 \mathrm{pm}$. An essential component of the volunteer role was gaining information about the patient's background and personal preferences from the person or their family member. The role of the volunteer was similar to that of a family carer. The specific care they provided included:

1. supporting orientation and interaction with others;

2. engagement in therapeutic activities;

3. promoting the use of visual and hearing aids;

4. assisting with eating and drinking; and

5. where safe and appropriate, encouraging regular walking.

Volunteers provided care for one or more patients over a shift, with care being prioritized, in consultation with nursing staff, to patients most in need. Thus, some patients may have received twice daily sessions and others only one or more ad-hoc 
sessions, depending on patient need and availability of volunteers.

\section{Outcome measures}

All patients had their medical record audited after discharge by a researcher with a clinical background in nursing, psychology, or physiotherapy. Information gathered included:

\section{DEMOGRAPHICS}

Date of birth, gender, type of residence preadmission and post-discharge (e.g. independent living, residential aged care facility (RACF), and residential respite).

CO-MORBIDITY

All diagnoses including delirium, dementia, and physical comorbidities (e.g. hypertension).

\section{Medication USE}

Regular and pro re nata (PRN) medications listed at admission and at discharge, all doses of PRN analgesia and PRN psychotropic medication (i.e. antipsychotics, benzodiazepines, and mood stabilizers, including lithium and anticonvulsant class mood stabilizers).

AdMission Details

Admission date, discharge date, referral reasons, whether re-admitted within 28 days.

\section{AdVERSE INCIDENTS}

All reportable adverse incidents as recorded in the Incident Information Management System (e.g. pressure area, aggression, and falls).

\section{BEHAVIORAL INCIDENTS}

A count of all behavioral incidents noted in the medical record progress notes for the entire admission. Patients who remained in hospital for longer than 14 days had only the first seven and last seven days of the admission coded for behavioral incidents.

\section{SPECIALLING}

Any episodes of a patient being provided with a 1:1 nurse or security guard specialling was recorded from the medical record notes.

\section{VOLUNTEER INVOLVEMENT}

For intervention group patients, the date the volunteer commenced and the number of volunteer sessions provided was recorded for the entire LOS. 
Table 3. Null multilevel models and intra-class correlations for outcome measures

\begin{tabular}{|c|c|c|c|c|c|c|}
\hline OUTCOME & $\begin{array}{l}\text { INTERCEPT } \\
\text { ESTIMATE }\end{array}$ & $\begin{array}{l}\text { STANDARD } \\
\text { ERROR }\end{array}$ & $\begin{array}{l}\text { RESIDUAL } \\
\text { ESTIMATE }\end{array}$ & $\begin{array}{l}\text { INTRA-CLASS } \\
\text { CORRELATION } r\end{array}$ & z & SIG. \\
\hline Length of Stay & 0.005 & 0.005 & 0.106 & 0.002 & 1.182 & 0.237 \\
\hline Discharge medications $(N)$ & 0.386 & 0.340 & 13.653 & 0.001 & 1.136 & 0.256 \\
\hline Specialled & 0.724 & 0.628 & 1.000 & 0.137 & 1.153 & 0.249 \\
\hline Died in hospital & 0.000 & - & 1.000 & 0.000 & 0.000 & - \\
\hline $\begin{array}{l}\text { Discharged to residential } \\
\text { care }\end{array}$ & 0.444 & 0.334 & 1.000 & 0.057 & 1.329 & 0.184 \\
\hline Any behaviors & 0.232 & 0.194 & 1.000 & 0.016 & 1.195 & 0.232 \\
\hline $\begin{array}{c}\text { Prescribed PRN } \\
\text { Psychotropics }\end{array}$ & 0.118 & 0.101 & 1.000 & 0.004 & 1.160 & 0.246 \\
\hline Given PRN Psychotropics & 0.129 & 0.132 & 1.000 & 0.005 & 0.976 & 0.329 \\
\hline $\begin{array}{l}\text { Prescribed psychotropics } \\
\text { at discharge }\end{array}$ & 0.007 & 0.040 & 1.000 & 0.000 & 0.170 & 0.865 \\
\hline Any falls & 0.000 & - & 1.000 & 0.000 & 0.000 & - \\
\hline Pressure area & 0.000 & - & 1.000 & 0.000 & 0.000 & - \\
\hline Readmitted $<28$ days & 0.076 & 0.142 & 1.000 & 0.002 & 0.531 & 0.595 \\
\hline Prescribed PRN analegesia & 0.035 & 0.064 & 1.000 & 0.000 & 0.547 & 0.584 \\
\hline Given PRN analgesia & 0.017 & 0.065 & 1.000 & 0.000 & 0.269 & 0.788 \\
\hline
\end{tabular}

\section{Data analysis}

The sample size of 458 is considered sufficient to detect medium to large effect sizes (Cohen's $\omega=$ $0.28-0.55 ; \mathrm{p}=0.05 ; 80 \%$ power) for $\chi^{2}$ analyses (Fleiss et al., 2003) and is sufficient to detect an $R^{2}$ value of $0.25(\mathrm{p}=0.05 ; 80 \%$ power $)$ for regression analyses (Soper, 2017).

Inter-rater reliability of the number of behavioral incidents identified by coders in the medical record notes was assessed on a random sample of $15.5 \%$ of files using a two-way, mixed, consistency intraclass correlation (ICC) (Hallgren, 2012). The ICC ( $\rho=0.889)$ was in the excellent range (Cicchetti, 1994), indicating that coders had a high degree of agreement.

In order to determine if multilevel modeling was required to take account of the correlation between outcomes for individuals in each hospital, ICCs were calculated for each (Tabachnick and Fidell, 2007; Heck et al., 2012). In order to meet the assumptions of multilevel modeling, LOS had seven outliers removed ( $z$ scores $>3.29$ ) and was logarithmically transformed. Number of behaviors, falls, pressure areas, and doses of PRN medications (divided by LOS) were unable to be transformed to meet assumptions of normality. These variables were transformed to dichotomous variables (any behaviors/falls/pressure areas/PRN medications) and analyzed using logistic multilevel modeling. Table 3 indicates that all ICCs are low and non-significant $(\mathrm{p}>0.05)$ (Tabachnick and Fidell, 2007; Heck et al., 2012). Therefore, there is no meaningful average difference between hospitals on the outcomes, permitting data to be analyzed at the individual level.

As such, independent $t$-tests or non-parametric means comparison (Mann-Whitney $U$ ) were conducted to determine if there were any statistically significant differences between the demographic profiles and outcomes of control and intervention groups (see Table 2). Sequential multiple and logistic regression analyses were conducted on regular and PRN discharge medications controlling for medications at admission at the first step and condition (control vs. intervention group) at the second step. Unless otherwise stated, analysis of regression residuals indicated that assumptions of normality, linearity, and homoscedasticity were met. No multivariate outliers were identified (Malhanobi's distance $\mathrm{p}<0.001$ ). No suppressor variables were found. Unless otherwise stated, where $N<458$, this is due to missing data in a random pattern.

\section{Results}

\section{Volunteer involvement}

Patients in the intervention group were provided with a median of five volunteer sessions $(M=7.28$, $\mathrm{SD}=8.69$, Range 1-69). There were no formal complaints, or clinical or other incidents reported as a result of volunteer involvement. 


\section{Length of stay}

The distribution for LOS was highly positively skewed and seven outliers were identified. However, these represented genuine data and were therefore included in non-parametric MannWhitney U test analysis. Table 4 presents descriptive statistics and $p$ values for group differences for continuous and dichotomous outcome measures. The intervention group had a statistically significantly longer LOS than the control group $(z=3.22$, $\mathrm{p}=0.001, d=0.30$ ).

\section{Behavioral incidents}

Due to large variation in LOS for patients, data on number of behavioral incidents were divided by LOS, yielding average behavioral incidents per day for each patient. Data were nonnormal and contained a large number of valid zero values and outliers. A Mann-Whitney U test indicated there were no differences between control and intervention groups in mean number of behavioral incidents per day $(z=1.725$, $\mathrm{p}=0.084)$.

\section{8-Day readmission}

28-day readmission rates for the intervention group $(8.6 \%)$ were significantly lower than the control group $\left(17.0 \% ; \chi^{2}(1, N=457)=\right.$ $7.501, \mathrm{p}=0.006)$. Effect size was small $(d=0.26)$

\section{Specialling}

A significantly smaller proportion of patients in the intervention group $(4.8 \%$ vs. $11.2 \%)$ required $1: 1$ nurse or security guard specialling $\left(\chi^{2}(1, N=458)\right.$ $=6.51, \mathrm{p}=0.011)$. Effect size was small $(d=0.24)$.

\section{Mortality}

There were no differences in mortality rates between the intervention (5.6\%) and control $(4.8 \%)$ groups $\left(\chi^{2}(1, N=455)=0.120, \mathrm{p}=\right.$ $0.729)$.

\section{First time admission to residential aged care}

There were no differences in the proportion of patients who were admitted from independent living but discharged to permanent RACF for the first time in the intervention versus control groups $\left(\chi^{2}(1, N=458)=2.13, \mathrm{p}=0.145\right)$.

\section{Falls}

Only $42(9.2 \%)$ patients fell between 1 and 3 times $($ Control $=8.6 \%$; Intervention $=9.6 \%)$. The distribution of number of falls divided by LOS was non-normal and unable to be transformed. A
Mann-Whitney $U$-test indicated that there were no statistically significant differences between groups in the number of falls per day $(z=0.430, \mathrm{p}=$ 0.667).

\section{Pressure ulcers}

Pressure ulcers were a rare event with only 15 (3.3\%) recorded in incident reports. There were no differences in the proportion of patients with pressure areas in each group $\left(\chi^{2}(1, N=458)=\right.$ $0.202, \mathrm{p}=0.653$ ).

\section{Medication use}

OVERALL MEDICATION AT DISCHARGE

Due to missing or unclear discharge medication documentation in two sites there was a higher proportion of missing data for discharge and PRN medications (approximately 5\%). Table 5 displays unstandardized regression coefficients (B), and intercept, standardized regression coefficients (beta), and $R^{2}$ and Adjusted $R^{2}$ after entry of all predictors.

Only the number of medications at admission reliably predicted the number of discharge medications $(p<0.001)$. There were no differences between groups $(\mathrm{p}=0.555)$. The full model accounted for $59 \%$ of the variance in discharge medications and was statistically significant $(\mathrm{p}<$ 0.001).

\section{PSYCHOTROPIC MEDICATION}

As seen in Table 4, patients in the intervention group were less likely to have prescriptions written for PRN psychotropic medication $(31.3 \%$ vs. $\left.53.2 \% ; \chi^{2}(1, N=454)=21.85, p<0.001\right)$ but, unfortunately the rate of PRN psychotropic administration did not differ for the intervention $(31.5 \%)$ and control groups $(29.2 \% ; z=0.313$, $\mathrm{p}=0.755)$. That is, all those in the intervention group who were prescribed PRN psychotropics were administered at least one dose, whereas 53\% of control group patients were prescribed PRN psychotropics, staff only used the prescription for $29 \%$ of patients. Similarly, logistic regression analyses indicate that, after controlling for whether patients were prescribed regular psychotropic medication at admission ( $\mathrm{p}<0.001)$, both groups were equally as likely to be prescribed regular psychotropics at discharge $(\mathrm{p}=0.490)$. The full regression model accounted for $51 \%$ of the variance in discharge medications and was statistically significant $(\mathrm{p}<0.001)$.

\section{ANALgeSic MEDiCATION}

Similar proportions of patients in both groups were prescribed PRN analgesia $(67 \%$ vs. $61 \%$; 
Table 4. Outcome measure descriptive statistics and $p$ values for group differences

\begin{tabular}{|c|c|c|c|c|c|c|c|c|c|}
\hline \multirow[b]{2}{*}{ OUTCOME（CONTINUOUS） } & \multicolumn{2}{|c|}{ CONTROL } & \multicolumn{3}{|c|}{ INTERVENTION } & \multicolumn{3}{|c|}{$A L L$} & \multirow[b]{2}{*}{ PVALUE } \\
\hline & $\mathrm{N}$ & MEAN（SD） & MEDIAN & MEAN（SD） & MEDIAN & MEAN（SD） & MEDIAN & RANGE & \\
\hline Length of Stay (days) & 458 & $9.14(8.79)$ & 6 & $11.75(11.78)$ & 9 & $10.68(10.72)$ & 7 & $1-83$ & 0.001 \\
\hline Behavioral incidents/LOS & 458 & $1.04(1.28)$ & 0.600 & $1.17(1.12)$ & 0.845 & $1.12(1.25)$ & 0.750 & $0-8.5$ & $0.084^{\mathrm{a}}$ \\
\hline Falls/LOS & & $0.010(.041)$ & 0 & $0.013(0.059)$ & 0 & $0.012(0.052)$ & 0 & $0-.05$ & 0.667 \\
\hline Number of Medications at discharge & 436 & $8.51(4.16)$ & & $8.34(3.43)$ & & $8.41(3.74)$ & 8 & $0-20$ & $0.555^{\mathrm{b}}$ \\
\hline Number of PRN psychotropic doses/LOS & 450 & $0.153(.339)$ & 0 & $0.191(.481)$ & 0 & $0.176(0.429)$ & 0 & $0-5$ & 0.755 \\
\hline Number of PRN analgesia doses/LOS & 402 & $0.507(.959)$ & 0.203 & $0.511(.721)$ & 0.167 & $0.510(0.815)$ & 0.196 & $0-9$ & 0.768 \\
\hline OUTCOME (YES) & CONTROL $N(\%)$ & INTERVENTION & $N(\%)$ & $\chi^{2}$ P VALUE & & & & & \\
\hline Readmitted $<28$ days & $32(17.0)$ & $23(8.6)$ & & 0.006 & & & & & \\
\hline Specialled & $21(11.2)$ & $13(4.8)$ & & 0.011 & & & & & \\
\hline Died in hospital & $9(4.8)$ & $15(5.6)$ & & 0.729 & & & & & \\
\hline Discharged to RACF & $15(8.0)$ & $33(12.2)$ & & 0.145 & & & & & \\
\hline Pressure ulcer & $7(3.7)$ & $8(3)$ & & 0.653 & & & & & \\
\hline Prescribed Psychotropics PRN & $99(53.2)$ & $84(31.3)$ & & 0.001 & & & & & \\
\hline Given PRN psychotropics & $54(29.2)$ & $84(31.5)$ & & 0.606 & & & & & \\
\hline Psychotropics at discharge & $72(40.0)$ & $89(34.2)$ & & $0.490^{\mathrm{b}}$ & & & & & \\
\hline Prescribed Analgesia PRN & $124(67.0)$ & $163(61.0)$ & & 0.194 & & & & & \\
\hline Analgesia at discharge & $105(64.4)$ & $164(63.6)$ & & $0.310^{\mathrm{b}}$ & & & & & \\
\hline
\end{tabular}

${ }^{a}$ Independent $t$-test.

${ }^{\mathrm{b}}$ See Table 5 for regression results. 
Table 5. Unstandardized regression coefficients (B), and intercept, standardized regression coefficients (beta), and $R^{2}$ and Adjusted $R^{2}$ for total number of medications at discharge, and whether on any psychotropics or analgesics at discharge

\begin{tabular}{|c|c|c|c|c|c|c|c|c|}
\hline VARIABLE & B & $S E B$ & BETA & $\mathrm{T}$ & SIG. & $\mathrm{R}^{2}$ & ADJUSTED R ${ }^{2}$ & $\mathrm{~F}$ \\
\hline \multicolumn{9}{|c|}{ Discharge medications $(N=433)$} \\
\hline Intercept & 2.252 & 0.309 & & 7.283 & 0.001 & 0.593 & 0.591 & $312.973^{*}$ \\
\hline Admission medications & 0.721 & 0.029 & 0.771 & 25.007 & 0.001 & & & \\
\hline \multirow[t]{2}{*}{ Condition } & 0.139 & 0.235 & 0.018 & 0.591 & 0.555 & & & \\
\hline & $\mathrm{B}$ & S.E. & WALD & DF & SIG. & $\operatorname{ExP}(\mathrm{B})$ & COX \& SNELL $R^{2}$ & $\chi^{2}(\mathrm{DF})$ \\
\hline \multicolumn{9}{|c|}{ Psychotropics discharge $(N=434)$} \\
\hline Psychotropics at admission & -4.546 & 0.340 & 178.580 & 1 & 0.001 & 0.011 & 0.510 & $309.62(2)^{*}$ \\
\hline Condition & 0.236 & 0.341 & 0.477 & 1 & 0.490 & 1.266 & & \\
\hline Intercept & 1.988 & 0.291 & 46.753 & 1 & 0.001 & 7.301 & & \\
\hline \multicolumn{9}{|l|}{ Analgesics discharge $(N=420)$} \\
\hline Analgesics at admission & -5.218 & 0.415 & 157.799 & 1 & 0.001 & 0.005 & 0.558 & $343.37(2)^{*}$ \\
\hline Condition & 0.397 & 0.391 & 1.031 & 1 & 0.310 & 1.487 & & \\
\hline Intercept & 3.174 & 0.359 & 78.176 & 1 & 0.001 & 23.899 & & \\
\hline
\end{tabular}

${ }^{*} \mathrm{p}<0.001$

$\left.\chi^{2}(1, N=452)=1.69, p=0.184\right)$. Both groups were administered a similar number of doses of PRN analgesia per day (Mann-Whitney $z=0.295, \mathrm{p}=068)$. Logistic regression analyses indicate that, after controlling for whether patients were prescribed regular analgesia at admission $(\mathrm{p}<0.001)$, both groups were equally as likely to be prescribed regular analgesia at discharge $(\mathrm{p}=$ 0.310 ). The full regression model accounted for $56 \%$ of the variance in discharge medications and was statistically significant $(\mathrm{p}<0.001)$.

\section{Discussion}

The present study aimed to compare the clinical outcomes for patients involved in the Dementia and Delirium Care with Volunteer Program $\mathbb{C}$ with historical control patients at seven rural hospitals in Southern NSW. Patients in the volunteer group had a significantly longer LOS but reduced 28 day readmission and 1:1 specialling rates. The volunteer group was less likely to be prescribed PRN psychotropic medication, but the same proportion of control and intervention groups were actually administered one or more doses of PRN psychotropic medication. There were no differences in other outcomes including falls, pressure ulcers, mortality, behavioral incidents, first time admission to RACF, and medication use. Future papers will report on cost-effectiveness and qualitative feedback on the program from family carers, hospital staff and volunteers.

\section{Strengths and limitations}

The trial was controlled by an historical control group selected from the same hospitals as the intervention group. This ensured a highly comparable sample of patients, staff and settings. Fidelity of program implementation was also assured through a use of a consistent implementation package, mentoring and site visits for all implementation officers. Multilevel modeling indicates that outcomes were consistent across sites.

The study was limited by a lack of resources to collect data on nutrition and hydration for either group. It was not possible to randomize patients due to contamination. Nor was it possible to blind data collection as patient files identified volunteer involvement. Given there were fifteen outcome measures, the chance of a type 1 error rate is inflated $(53 \%, \mathrm{p}=0.05)$.

\section{Efficacy and quality of care}

Given the evidence that acute hospital stays can be a very negative and distressing experience for people with cognitive impairment (Dewing and Dijk, 2016), the reduction in 28 day readmission rates is a very positive outcome and may lead to improved longer term outcomes for patients with cognitive impairment. Readmission rates are used as a key quality indicator and may be linked to payment incentives or penalties for public hospitals in the future. 
The increase in LOS associated with the volunteer program is inconsistent with previous studies on volunteer involvement in acute care (Caplan and Harper, 2007; Bateman et al., 2016). However, most volunteer programs in metropolitan areas are augmented by geriatricians and other staff specialists (Caplan and Harper, 2007; Rubin et al., 2011). Such resources were unavailable in the current study and in many rural hospitals. As such, it may be unrealistic to expect volunteers alone to impact a complex hospital system to the extent that LOS is reduced. Alternatively, there is international evidence to suggest that increase in LOS together with a reduction in 28 day readmission rates are linked and may be indicative of increased quality of care (Eapen et al., 2013).

The reduction in rates of patients requiring 1:1 specialling is consistent with another Australian volunteer study (Caplan and Harper, 2007). Although often aimed at keeping patients safe, specialling is often conducted by nursing staff or hospital security staff with limited training in person-centered care or trauma informed care, little knowledge of the patient's background, and can involve physical restraint (Moyle et al., 2011). It is often at best, non-therapeutic "babysitting." The current finding suggests that the person-centered care provided by volunteers may provide a more therapeutic interaction which replaces the need for, and costs associated with, specialling.

Although the rates of psychotropic medication use, particularly $P R N$ use did not differ for the intervention and control groups, approximately $30 \%$ of the sample were prescribed and administered psychotropics. This indicates that, despite the risks involved, this practice is still used often for patients with dementia and delirium and therefore well entrenched. However, fewer patients in the intervention group $(31.3 \%$ vs. $53.2 \%)$ were prescribed PRN psychotropics, indicating a change in prescribing practices by doctors but no change in administration rates by nurses. Further intervention with both medical and nursing staff is required to reduce the use of potentially unsafe medications in older patients. Volunteers may provide an alternative to chemical restraint in acute care, particularly if engaged early in the admission before confusion and other problems escalate.

\section{Safety}

The findings that there were no changes to falls, pressure ulcers, mortality, admission to residential care and behavioral incidents indicate that the volunteer program is a safe intervention. Rigorous selection and ongoing training and mentoring of volunteers ensured that volunteers acted within the boundaries of their role and did not pose a risk to patients as indicated by no increases in falls or other incidents.

\section{Implementation and resourcing}

Future papers will report on the cost effectiveness and challenges and enabling factors associated with the program for volunteers, staff and family members. However, it is important to note here that the program did require financial, physical and personnel resources to set up and maintain. These costs may, however, be offset by savings associated with reduced specialling and 28 day readmission. It is also important to note that volunteers are not a substitute for professionals; they complement and augment professional roles and provide respite for families by providing the services that family members and friends often provide.

\section{Conclusion}

The Dementia and Delirium Care with Volunteer's program was successfully implemented in 7 rural hospitals of varying sizes and resulted in reductions in 28 day readmission and specialling rates. That there were no increases in falls, pressure ulcers, mortality or institutionalization indicates the intervention is safe. The implementation package and mentoring resulted in consistent implementation and results across all sites. These results indicate that the Dementia and Delirium Care with Volunteer's program is a safe, effective, and scalable intervention to improve the quality of care provided for older people admitted to acute hospitals with dementia, delirium, or who are at risk of delirium.

\section{Conflict of interest}

No conflict of interest has been declared by the authors.

\section{Description of authors' roles}

C. Bateman, A. Blair, and K. Anderson contributed equally to this work. C. Bateman developed the program, conducted the initial pilot, developed the implementation and training resources, advised on the use of clinical research measures, and revised the manuscript. A. Blair prepared the ethics, selected survey tools, assisted in conceptualizing the study, analyzed data, and drafted the manuscript. $K$. Anderson guided the research team, gained funding for the project, conceptualized the study, 
developed measures, contributed to data analysis, and revised this manuscript. All authors read and approved the final manuscript.

\section{Acknowledgments}

This project is supported by the Southern NSW Local Health District staff, who have gone above and beyond their usual duties to assist in implementation. We thank the NSW Health Agency for Clinical Innovation for funding the development of the Volunteer Dementia and Delirium Care Implementation and Training resource (C) and for providing copies of the resource package as in-kind support. We are grateful for the support provided by the NHMRC Partnership Centre on Dealing with Cognitive and Related Functional Decline in Older People (CDPC) and the strong CDPC consumer representatives who assisted. We thank all the "Golden Angel" volunteers, staff, patients, and families for their feedback and ongoing support for the project. This project was funded through the Australian Commonwealth Department of Health, Aged Care Service Improvement and Healthy Ageing Grants. The views expressed are those of the authors and not necessarily those of the Australian Government.

\section{References}

Bateman, C., Anderson, K., Bird, M. and Hungerford, C. (2016). Volunteers improving person centred dementia and delirium care in a rural hospital. Rural and Remote Health, 16, 3667.

Caplan, G. A. and Harper, E. L. (2007). Recruitment of volunteers to improve vitality in the elderly: the REVIVE* study. Internal Medicine fournal, 37, 95-100.

Cicchetti, D. V. (1994). Guidelines, criteria, and rules of thumb for evaluating normed and standardized assessment instruments in psychology. Psychological Assessment, 6, 284.

Clissett, P., Porock, D., RH, H. and Gladman, J. R. (2013). The challenges of achieving person-centreted care in acute hospitals: a qualitative sutdy of people with dementia and their families. International Fournal of Nursing Studies, 50, 1495-1503.

Dewing, J. and Dijk, S. (2016). What is the current state of care for older people with dementia in general hospitals? A literature review. Dementia, 15, 106-124. doi:10.1177/1471301213520172.

Eapen, Z. J. et al. (2013). Do Countries or hospitals with longer hospital stays for acute heart failure have lower readmission rates? Circulation: Heart Failure, 6, 727-732.

Fleiss, J. L., Levin, B. and Paik, M. C. (2003). Statistical Methods for Rates and Proportions. Hoboken, NJ: J. Wiley.

Hallgren, K. A. (2012). Computing inter-rater reliability for observational data: an overview and tutorial. Tutorials in Quantitative Methods for Psychology, 8, 23.
Heck, R. H., Thomas, S. and Tabata, L. N. (2012). Multilevel Modeling of Categorical Outcomes Using IBM SPSS. New York: Routledge.

Hshieh, T. T. et al. (2015). Effectiveness of multicomponent nonpharmacological delirium interventions: a meta-analysis. $\mathcal{F A M A}$ Internal Medicine, 175, 512-520. doi:10.1001/jamainternmed.2014.7779.

Inouye, S. K., Bogardus, S. T., Baker, D. I., Leo-Summers, L. and Cooney, L. M. (2000). Models of geriatrics practice; the hospital elder life program: a model of care to prevent cognitive and functional decline in older hospitalized patients. Fournal of the American Geriatrics Society, 48, 1697-1706. doi:10.1111/j.1532-5415.2000.tb03885.x.

Inouye, S. K., Marcantonio, E. R. and Metzger, E. D. (2014). Doing damage in delirium: the hazards of antipsychotic treatment in elderly people. The Lancet. Psychiatry, 1, 312-315. doi:10.1016/S2215-0366(14)70263-9.

Inouye, S. K., Westendorp, R. G. J. and Saczynski, J. S. (2013). Delirium in elderly people. The Lancet, 383, 911-922. doi:10.1016/S0140-6736(13)60688-1.

Kitwood, T. (1997). Dementia Reconsidered: The Person Comes First. Buckingham: Open University Press.

Maust, D. T. et al. (2015). Antipsychotics, other psychotropics, and the risk of death in patients with dementia: number needed to harm. $\mathcal{F A M A}$ Psychiatry, 72, 438-445. doi:10.1001/jamapsychiatry.2014.3018.

Moyle, W., Borbasi, S., Wallis, M., Olorenshaw, R. and Gracia, N. (2011). Acute care management of older people with dementia: a qualitative perspective. Fournal of clinical nursing, 20, 420-428. doi:10.1111/j.1365-2702.2010.03521.x.

NSW Agency for Clinical Innovation. (2014). Volunteer Dementia and Delirium Care: $A$ hospital program implementation guide. Sydney: NSW Agency for Clinical Innovation.

Rizzo, J. A., Bogardus, S. T. Jr., Leo-Summers, L., Williams, C. S., Acampora, D. and Inouye, S. K. (2001). Multicomponent targeted intervention to prevent delirium in hospitalized older patients: what is the economic value? Medical Care, 39, 740-752.

Rubin, F. H., Neal, K., Fenlon, K., Hassan, S. and Inouye, S. K. (2011). Sustainability and Scalability of the hospital elder life program at a community hospital. fournal of the American Geriatrics Society, 59, 359-365. doi:10.1111/j.1532-5415.2010.03243.x.

Siddiqi, N et al. (2016). Interventions for preventing delirium in hospitalised non-ICU patients. Cochrane Database of Systematic Reviews. doi:10.1002/14651858.CD005563.pub3.

Sink, K., Holden, F. and Yaffe, K. (2005). Pharmacological treatment of neuropsychiatric symptoms of dementia: a review of the evidence. Fournal of the American Medical Association, 293, 596-608.

Soper, D. (2017). Free Statistics Calculators. 4th ed. Retrieved from https://www.danielsoper.com/statcalc/calculator.aspx?id=9.

Tabachnick, B. G. and Fidell, L. S. (2007). Using Multivariate Statistics (p. 822). Boston, MC: Pearson Education. Inc. 